\title{
Prevalence of overweight and obesity among young people in Great Britain
}

\author{
Susan A Jebb ${ }^{1, *}$, Kirsten L Rennie ${ }^{1}$ and Tim J Cole ${ }^{2}$ \\ ${ }^{1}$ MRC Human Nutrition Research, Elsie Widdowson Laboratory, Fulbourn Road, Cambridge CB1 9NL, UK: \\ ${ }^{2}$ Centre for Paediatric Epidemiology and Biostatistics, Institute of Child Health, 30 Guilford Street, \\ London WCIN 1EH, UK
}

Submitted 20 May 2003: Accepted 3 September 2003

\begin{abstract}
Objective: To determine the prevalence of overweight and obesity in British young people (4-18 years) in 1997.

Design: Cross-sectional analysis of the National Diet and Nutrition Survey of young people.

Setting: Great Britain.

Subjects: Nationally representative sample of 1836 young people (age 4-18 years). Results: The prevalence of obesity based on body mass index (weight/height ${ }^{2}$ ) and the International Obesity Task Force cut-offs was $4.0 \%$, with a further $15.4 \%$ identified as overweight. Asians were almost four times as likely to be obese as white subjects (13.6 vs. $3.5 \%, P<0.001)$. Among white subjects there was no significant difference in the prevalence of obesity between girls and boys, or with age. The risk of obesity was significantly higher in subjects from social classes IV and V than from social classes I-III (6.5 vs. $2.7 \%, P=0.003)$. Subjects living in Scotland and Wales were significantly more likely to be obese than those in England (7.6 and 6.5 vs. 2.9\%, respectively, $P<0.01$ ). Multiple logistic regression showed that, among white subjects, those in social classes IV and V living in Wales and Scotland were three times more likely to be obese than the other children in the survey (odds ratio 3.3, 95\% confidence interval 1.1-9.8).

Conclusion: These data provide information on the national prevalence of overweight and obesity in Great Britain and baseline data from which to monitor future trends. This analysis provides important demographic information on those most at risk of obesity, which may be used to inform public health strategies to prevent obesity in young people.
\end{abstract}

There is growing concern about the prevalence of obesity in Great Britain. Data from the 1998 Health Survey for England show that $19 \%$ of men and $21 \%$ of women are defined as obese, with a body mass index (BMI) greater than $30 \mathrm{~kg} \mathrm{~m}^{-2}$, an increase of almost threefold relative to $1980^{1}$. There are, however, few data on the secular trend in children because of a paucity of nationally representative surveys and lack of agreement over the definition of child obesity.

Data from the USA have shown a threefold increase in obesity in children (relative to US growth curves) in three decades and, today, $13-14 \%$ are obese ${ }^{2}$. Estimates in Europe vary from 3 to $21 \%$ depending on the definition of obesity used $^{3}$, with an estimated $10-17 \%$ in England ${ }^{4}$, each based on national reference growth data and using study-specific cut-offs for obesity. In 2000, the International Obesity Task Force proposed a reference dataset for the definition of overweight and obesity in children, derived from growth curves in six countries (Brazil, Great
Britain, Hong Kong, The Netherlands, Singapore and the USA), to facilitate international epidemiological comparisons of the prevalence and secular trends in obesity ${ }^{5}$. To date, only one study of 4-11-year-olds has used this methodology in a UK study. The National Survey of Health and Growth (NSHG) showed that the prevalence of obesity was approximately $2 \%$ in boys and 3\% in girls, and that the proportion of overweight children had risen by over $50 \%$ in the period 1984 to $1994^{6}$. However, it did not provide more demographic information to identify those children at greatest risk.

There is a pressing need to both prevent and treat obesity in children and young people. Excess weight gain at a young age increases the risk of obesity in later life ${ }^{7}$ and contributes to the burden of obesity-related disease. Risk factors for coronary heart disease have been reported in obese children and adolescents ${ }^{8}$ and cases of type 2 diabetes are emerging among obese adolescents 9 . Identifying those children at greatest risk of developing 
obesity is important for the development of effective public health strategies to prevent and treat excess weight gain and its associated co-morbidities.

The present study exploited data collected as part of the National Diet and Nutrition Survey (NDNS) to identify the prevalence of overweight and obesity in a nationally representative sample of young people in Great Britain in relation to demographic factors, and to provide baseline data from which to monitor future trends.

\section{Methods}

The NDNS is a nationally representative sample of 2127 young people aged 4-18 years studied in 1997. The sample was based on households, using a multistage random probability design with postal sectors as first-stage units and sub-sampling to ensure an equal number of boys and girls across all ages. A total of 2672 subjects were selected and $80 \%$ participated in the survey. The sample design has been described in more detail elsewhere ${ }^{10}$. From the 2127 subjects who participated, 1836 subjects had complete anthropometric data and were used in the analyses. Subjects who had anthropometric data were significantly younger than those who did not (mean (standard deviation) 10.8 (3.9) vs. 14.2 (4.9) years, $P<0.001$ ), but did not differ in terms of sex distribution, social class or region of residence.

Trained interviewers collected measurements of height and weight. Subjects were measured in minimal clothing and without shoes. Body mass index was calculated as weight $(\mathrm{kg})$ divided by the square of height $\left(\mathrm{m}^{2}\right)$. The international reference standard was used to define overweight and obesity ${ }^{5}$. This is based on average percentiles, which equate to a BMI of 25 or $30 \mathrm{~kg} \mathrm{~m}^{-2}$ at age 18 years for overweight or obesity, respectively, and in pooled data from six national growth surveys approximates to the 90th and 99th percentiles in boys and girls ${ }^{5}$. Here, obesity is defined as a BMI on or above the obesity cut-off, while overweight is a BMI on or above the overweight cut-off and below the obesity cut-off.

Demographic details were collected from each respondent and the parent of the respondent present at the interview by an investigator-led questionnaire. The occupation of the head of household was used to determine the social class of the index subject. In $10 \%$ of cases social class could not be derived and these subjects were unclassified. The respondent was asked to choose from a prompt card the range in which the household's annual gross income fell. This was split into above and below the reported median gross income (£20000) for analysis. Ethnicity was determined from self-rating by the respondent. In order to provide adequate numbers for analysis, data on the standard government regions of residence were collapsed into three categories corresponding to England, Wales and Scotland.
Chi-square tests were used to compare the prevalence of overweight and obesity in demographic subgroups. Multiple logistic regression was used to identify independent predictors of obesity, and significant predictors were used to calculate the odds of being obese. Adjustment for the timing or round of the survey interview did not change the results.

The prevalence of obesity and overweight from all 1836 subjects in the NDNS was compared with that from the Diets of British Schoolchildren survey in $1983^{11}$. The sample for this earlier survey was designed to give a representative sample of Great Britain in two age groups. It included 2092 10-11-year-old and 1266 14-15-year-old children, including children of minority ethnic origin. These data were re-analysed using the international reference standard to define overweight and obesity.

\section{Results}

The prevalence of obesity in the NDNS was $4.0 \%(n=73)$, with a further $15.4 \%(n=282)$ identified as overweight. Asian subjects were almost four times as likely to be obese as white subjects (13.6 vs. 3.5\%, $P<0.001$ ). Among Asian and Afro-Caribbean subjects the proportion of overweight plus obese subjects was similar and higher than that among white subjects ( 25.9 and 23.4 vs. $18.9 \%, P=0.06$ ) (Fig. 1). However, given the relatively small numbers of non-white subjects, further analyses were limited to white subjects only ( $n=1667)$.

There was no significant difference in the prevalence of obesity (4.2 vs. $2.9 \%$ ) or overweight plus obesity (20.3 vs. $17.6 \%$ ) between girls and boys. There was no significant difference in the prevalence of obesity between age groups, but there was a trend of increasing prevalence of overweight plus obesity with age in boys $(P=0.02)$ (Table 1).

There was an inverse relationship between obesity and social class, with a significantly higher prevalence of obesity in social classes IV and $\mathrm{V}$ than in classes I-III

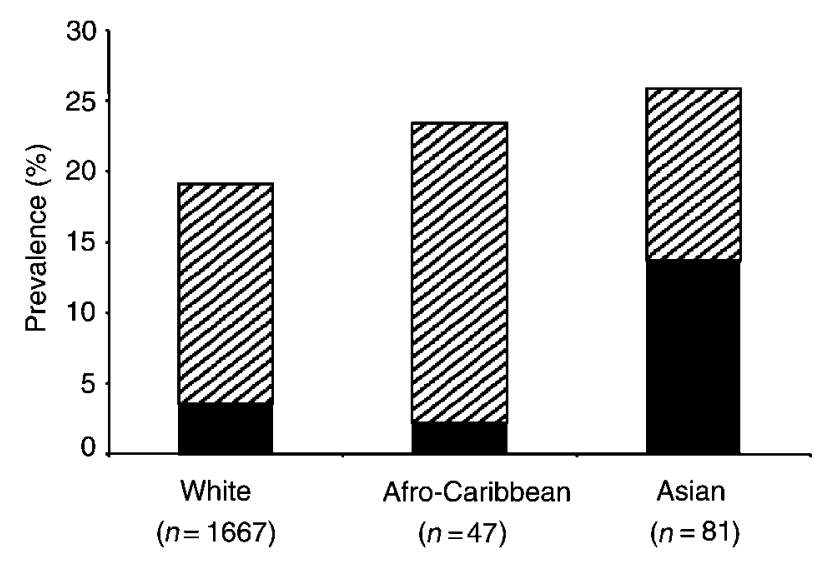

Fig. 1 Prevalence (\%) of overweight (hatched bars) and obesity (solid bars) by ethnic group in young people aged $4-18$ years in $1997(n=1795)$ 
Table 1 Prevalence of obesity and overweight plus obesity ${ }^{*}$ in 859 boys and 808 girls by age: $n(\%)$

\begin{tabular}{lccccc}
\hline & \multicolumn{2}{c}{ Boys } & & \multicolumn{2}{c}{ Girls } \\
\cline { 2 - 3 } \cline { 5 - 6 } $\begin{array}{l}\text { Age group } \\
\text { (years) }\end{array}$ & Obesity & $\begin{array}{c}\text { Overweight } \\
\text { plus obesity }\end{array}$ & & Obesity & $\begin{array}{c}\text { Overweight } \\
\text { plus obesity }\end{array}$ \\
\hline $4-6$ & $4(2.0)$ & $31(15.5)$ & & $6(3.3)$ & $38(20.7)$ \\
$7-8$ & $1(0.8)$ & $14(10.7)$ & & $4(4.3)$ & $23(24.7)$ \\
$9-11$ & $9(4.4)$ & $33(16.3)$ & & $6(3.1)$ & $43(22.4)$ \\
$12-14$ & $4(2.4)$ & $34(20.6)$ & & $10(5.9)$ & $27(15.8)$ \\
$15-17$ & $7(4.4)$ & $39(24.4)$ & & $8(4.8)$ & $33(19.6)$ \\
$P$-value for trend & 0.2 & 0.02 & & 0.7 & 0.4 \\
\hline
\end{tabular}

*Using International Obesity Task Force body mass index cut-offs.

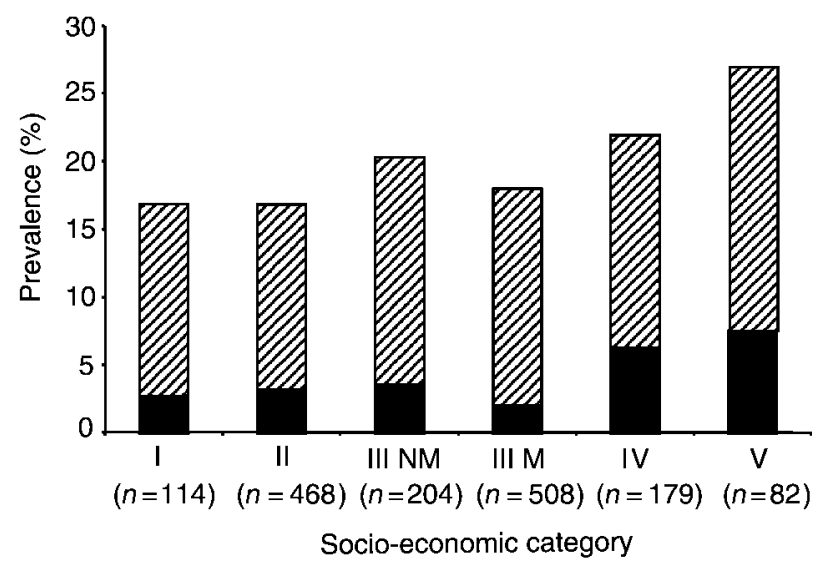

Fig. 2 Prevalence (\%) of overweight (hatched bars) and obesity (solid bars) by socio-economic category in young people aged 418 years in $1997(n=1555)$. Socio-economic category I-III vs. IV and V: obesity, $P=0.003$; obesity and overweight, $P=0.004$. $\mathrm{NM}$ - non-manual; M - manual

(6.5 vs. $2.7 \%, P=0.003$ ) and likewise a significant trend for overweight plus obesity (23.4 vs. $17.7 \%, P=0.04$ ) (Fig. 2). A significantly higher prevalence of overweight and obesity was observed in those households with annual income $<£ 20000$ compared with those with $\geq £ 20000$ ( 21.1 vs. $16.8 \%, P=0.03$ ) but this association was not found for obesity (3.5 vs. 3.6\%). Large regional variations in both obesity and overweight were observed. There was significant variation between countries, with more obese subjects in Scotland and Wales than in England (7.6 and 6.5 vs. $2.9 \%$, respectively, $P<0.001$ ) but not for overweight plus obesity ( 21.5 and 21.7 vs. $18.4 \%$, respectively).

Multiple logistic regression analysis in the white subjects demonstrated that country and low social class were significant and independent predictors of obesity. Those in social classes IV and V living in Wales and Scotland were more than three times as likely to be obese as the other children in the survey (odds ratio 3.3, 95\% confidence interval 1.1-9.8).

Comparison of the NDNS 1997 data with the 1983 survey of the Diets of British Schoolchildren showed an increase in the prevalence of overweight and obesity

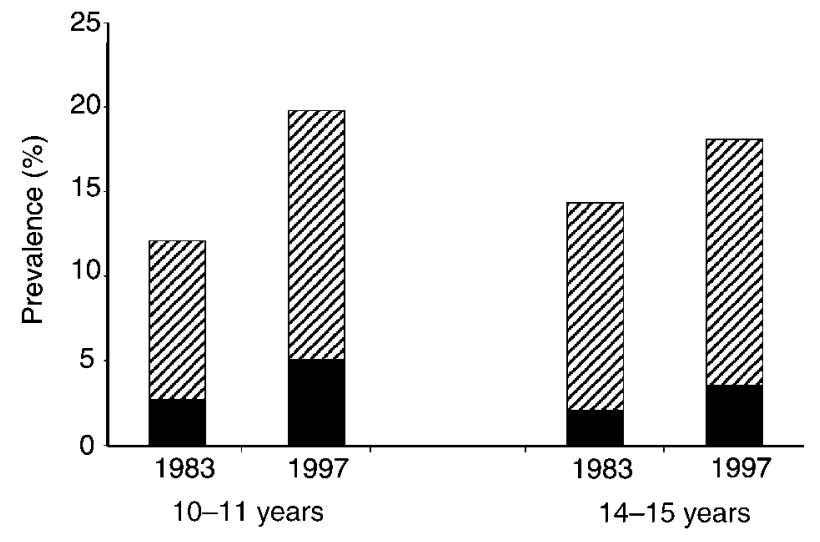

Fig. 3 Prevalence (\%) of overweight (hatched bars) and obesity (solid bars) in 1983 and 1997 among young people aged 10-11 years $(1983, n=2125 ; 1997, n=285)$ and $14-15$ years (1983, $n=1349 ; 1997, n=256)$. Difference in prevalence of overweight and obesity among 10-11-year-olds between 1983 and 1997: $P=0.03$

between 1983 and 1997 in both age groups, but the increase was significant only in the 10-11-year age group (obese: $P=0.04$, overweight: $P=0.007$ ) (Fig. 3).

\section{Discussion}

This paper presents the first results from a nationally representative sample of $4-18$-year-old young people in the UK in which the prevalence of overweight and obesity has been calculated based on the international reference standards. It provides an important baseline from which to study future trends in obesity and to monitor the impact of public health strategies. It has highlighted a particularly high prevalence of obesity in minority ethnic groups, especially among Asians. There is also a significantly higher prevalence of obesity in young people living in Scotland and Wales relative to their English counterparts. It has demonstrated that those living in a household with below median income or low social class are at increased risk. The social class trends observed in children are similar to those in UK adults ${ }^{12}$. A higher prevalence of obesity with lower social class has been reported in other countries ${ }^{13,14}$ but has been inconsistent, especially in children $^{13,15}$. The differences observed by geographical region were independent of social class. More research is needed to understand the lifestyle factors underpinning this differential risk of obesity. In particular, the strikingly high prevalence of obesity in Asians needs to be addressed since Asians are at increased risk of later cardiovascular disease and diabetes compared with white children, even at similar $\mathrm{BMI}^{16}$.

Previous data in Great Britain have often focused on a specific age group ${ }^{17}$ or geographical area ${ }^{18,19}$, limiting their generalisability. Data from the 1996 Health Survey for England have been analysed by using a compilation of 1978-1990 UK reference growth curves ${ }^{4}$. Among 6-15year-olds the prevalence of overweight $(>85$ th BMI 
percentile) was $22-31 \%$ and obesity ( $>95$ th percentile) affected $10-17 \%$ of the sample. The much higher prevalence than reported in this NDNS dataset is likely to be attributable to the difference in reference datasets and highlights a fundamental problem in using arbitrary cut-offs. Since there is no link between prevalence estimates in young people using the 95th percentile and the classification of obesity in adults, there is apparently an abrupt decline in obesity at the point of transfer to the adult classification system, since the Health Survey for England in 1996 identifies only $6.1 \%$ of men and $7.9 \%$ of women (16-24 years) as obese ${ }^{1}$. In contrast, estimates made using the international reference data track consistently from adolescence into adulthood, making them a valuable resource for epidemiological comparisons, although their clinical validity requires further analysis of the links to long-term health outcomes.

The NSHG is the only previous study in Great Britain to use the international cut-offs ${ }^{6}$. This was a large sample of 30755 children aged from 4 to 11 years. Sampling was conducted on a school basis, with weighting towards poorer areas rather than a random individual sampling frame as for the NDNS. Comparison of the two surveys for 4-11-year-olds indicates that the prevalence of obesity in England has continued to rise steadily from the last NSHG survey in 1993/94 to the present NDNS in 1997, although there appears to have been a marked increase in Scotland.

Comparison of the NDNS data with the previous Diets of British Schoolchildren survey shows a significant increase in overweight and obesity in the 10-11-year but not the 14-15-year age group. Interpretation of this finding is limited by the much larger sample size in the 1983 survey, but may suggest that younger children are getting fatter faster than older children. Alternatively, it may reflect broader changes in growth pattern, perhaps including the effect of earlier puberty in the 1997 NDNS sample.

BMI is highly specific but has low sensitivity for identifying overweight children ${ }^{20}$. Since obesity is characterised by excess fat, there is a need for largescale monitoring of fatness per se in children. There are other NDNS data to suggest that the secular increase in fatness, based on waist circumference, may exceed the increase in $\mathrm{BMI}^{21}$. This would be consistent with decreases in the lean/fat ratio as a consequence of reduced levels of physical activity. It implies that the reported increase in the prevalence of obesity, based on BMI, may be an underestimate of the true extent of the problem. Recent developments in bio-impedance technology may make measurements of body fat feasible for future surveys.

This cross-sectional survey cannot determine any causal relationships. Nevertheless, the findings provide important demographic insights into the growing problem of obesity in young people. Further research is required in prospective studies to determine the underlying lifestyle behaviours contributing to this problem. Particular emphasis should be placed on the most vulnerable children, including those from minority ethnic groups, children living in Scotland and Wales and in low social class.

\section{Acknowledgements}

The authors wish to thank the NDNS Project Board, Essex Data Archive.

\section{References}

1 Joint Health Surveys Unit on behalf of the Department of Health. Health Survey for England: Cardiovascular Disease 1998. London: The Stationery Office, 1999.

2 Centers for Disease Control and Prevention. National Health and Nutritional Survey. Overweight among US Children and Adolescents [online], 2000. Available at http://www.cdc.gov/ nchs/nhanes.htm.

3 Livingstone MBE. Epidemiology of childhood obesity in Europe. European Journal of Pediatrics 2000; 159(Suppl. 1): S14-34.

4 Reilly JJ, Dorosty AR. Epidemic of obesity in UK children. Lancet 1999; 354: 1874-5.

5 Cole TJ, Bellizzi MC, Flegal KM, Dietz WH. Establishing a standard definition for child overweight and obesity worldwide: international survey. British Medical Journal 2000; 320: 1240-3.

6 Chinn S, Rona RJ. Prevalence and trends in overweight and obesity in three cross sectional studies of British children, 1974-94. British Medical Journal 2001; 322: 24-6.

7 Whitaker RC, Wright JA, Pepe MS, Seidel KD, Dietz WH. Predicting obesity in young adulthood from childhood and parental obesity. New England Journal of Medicine 1997; 337(13): 869-73.

8 Sinha R, Fisch G, Teague B, Tamborlane WV, Banyas B, Allen $\mathrm{K}$, et al. Prevalence of impaired glucose tolerance among children and adolescents with marked obesity. New England Journal of Medicine 2002; 346(11): 802-10.

9 Drake AJ, Smith A, Betts PR, Crowne EC, Shield JPH. Type 2 diabetes in obese white children. Archives of Disease in Childhood 2002; 86: 207-8.

10 Gregory J, Lowe S. National Diet and Nutritional Survey: Young People aged 4 to 18 years. Vol. 1. Report of the Diet and Nutrition Survey. London: The Stationery Office, 2000 .

11 Department of Health. The Diets of British Schoolchildren. Sub-committee on Nutritional Surveillance, Committee on Medical Aspects of Food Policy. London: Her Majesty's Stationery Office, 1989.

12 Jebb SA, Prentice AM, Cole TJ. Obesity and social class in women: effects of smoking, drinking and physical activity. Proceedings of the Nutrition Society 1997; 56: 159A.

13 Wang Y. Cross-national comparison of childhood obesity: the epidemic and the relationship between obesity and socioeconomic status. International Journal of Epidemiology 2001; 30: 1129-36.

14 McMurray RG, Harrell JS, Deng S, Bradley CB, Cox LM, Bangdiwala SI. The influence of physical activity, socioeconomic status, and ethnicity on the weight status of adolescents. Obesity Research 2000; 8(2): 130-9.

15 Sobal J, Stunkard AJ. Socioeconomic status and obesity: a review of the literature. Psychological Bulletin 1989; 105 : $260-75$.

16 Whincup PH, Gilg JA, Papcosta O, Seymour C, Miller GJ, Alberti KG, et al. Early evidence of ethnic differences in cardiovascular risk: cross sectional comparison of British 
South Asian and white children. British Medical Journal 2002; 324: 1-6.

17 Bundred P, Kitchiner D, Buchan I. Prevalence of overweight and obese children between 1989 and 1998: population based series of cross sectional studies. British Medical Journal 2001; 322: 1-4.

18 Rudolf MCJ, Sahota P, Barth JH, Walker J. Increasing prevalence of obesity in primary school children: cohort study. British Medical Journal 2001; 322: 1094-5.

19 Reilly JJ, Dorosty AR, Emmett PM. Prevalence of overweight and obesity in British children: cohort study. British Medical Journal 1999; 319: 1039.

20 Mast M, Langnase K, Labitzke K, Bruse U, Preuss U, Muller MJ. Use of BMI as a measure of overweight and obesity in a field study on 5-7 year old children. European Journal of Nutrition 2002; 41: 61-7.

21 McCarthy HD, Ellis SM, Cole TJ. Waist circumference in British children aged 11-16 years 1977-1997: dramatic increases in central overweight and obesity. British Medical Journal 2002; 326: 624. 